\title{
Question-Embedding and Factivity
}

\author{
Paul Égré \\ (CNRS, IJN, Paris)
}

$18 / 11 / 2007$

First Version

\begin{abstract}
Attitude verbs fall in different categories depending on the kind of complements which they can embed. In English, a verb like know takes both declarative and interrogative complements. By contrast, believe takes only declarative complements and wonder takes only interrogative complements. The present paper examines the hypothesis, originally put forward by Hintikka 1975, that the only verbs that can take both that-complements and whether-complements are the factive verbs. I argue that at least one half of the hypothesis is empirically correct, namely that all veridical attitude verbs taking that-complements take whether-complements. I distinguish veridical verbs from factive verbs, and present one way of deriving the generalization. Counterexamples to both directions of the factivity hypothesis are discussed, in particular the case of emotive factive verbs like regret, and the case of nonveridical verbs that licence whether-complements, in particular tell, guess, decide and agree. Alternative accounts are discussed along the way, in particular Zuber (1982), Ginzburg (1995) and Saebo (2006).
\end{abstract}

\section{Introduction: the factivity hypothesis}

Attitude verbs in English fall in different categories depending on the kind of complements which they can embed. In English, a verb like know takes both declarative and interrogative complements. By contrast, a verb like believe takes only declarative complements. A verb like wonder, on the other hand, takes only interrogative complements:

(1) a. Pierre knows that it is raining

b. Pierre believes that it is raining

c. *Pierre wonders that it is raining

(2) a. Pierre knows whether it is raining

b. *Pierre believes whether it is raining

c. Pierre wonders whether it is raining 
These contrasts in embedding behavior do not hold only for English but are widely supported by cross-linguistic data (Karttunen 1977, Ginzburg 1995, Lahiri 2002). The contrast between wonder and know, in particular, plays an important role in the theory of questions put forward by Groenendijk and Stokhof (1982), and serves as the basis of their distinction between the intension and the extension of a question (to which we shall return). To some extent, the opposition between know and believe has been less systematically studied, despite a number of observations on the contrast, both by philosophers and by linguists (Vendler 1972, Hintikka 1975, Lewis 1982, Zuber 1982, Groenendijk and Stokhof 1982, Berman 1991, Ginzburg 1995, Lahiri 2002, and more recently, Saebo 2006).

In his paper, however, Hintikka observed that the difference in questionembedding behavior between know and believe seems to be correlated with the factive vs. non-factive feature of each of the two verbs. Thus, Hintikka conjectured that "only verbs which can have a success force may enter into a wh-construction" (Hintikka 1975: 21). For instance, non-factive verbs used to report belief, like pretend or claim are non-factive and do not appear to embed questions. On the other hand, attitude verbs like see, remember, forget, which also bear a semantic connection to know, are both factive and question-embedding.

Despite this, Hintikka did not provide a detailed explanation of the link between factivity and question-embedding behavior. The aim of the present paper is to take a closer look at this connection, namely to examine how robust it is and how it may be derived. Let us call Hintikka's hypothesis the factivity hypothesis, that is the hypothesis according to which the only verbs that take both declarative and interrogative complements are the factive verbs. The factivity hypothesis raises immediately two problems: the first concerns the definition of the notion of factivity that is relevant in the formulation of the hypothesis. Among philosophers and logicians, a predicate is generally called factive if it is simply veridical, namely if it entails the truth of its complement (see e.g. Williamson 2000). Among linguists, a predicate is usually called factive if it presupposes the truth of its complement (Kiparsky \& Kiparsky 1970, Karttunen 1971). Which of these two definitions is most relevant is of central importance to test the empirical adequacy of the generalization, which is the second main problem raised by the hypothesis.

Thus, verbs like tell or decide are not veridical, and yet they admit whethercomplements. This suggests that veridicality is not a necessary condition in order for a verb that takes that-complements to also embed questions. Conversely, as pointed out by Lahiri (2002), a verb like regret is generally considered factive and veridical, but it does not admit whether-complements. This suggests that factivity is not even a sufficient condition for verbs that take that-complements to embed questions. In what follows, however, I want to suggest that at least one half of the factivity hypothesis is correct. More precisely, my suggestion is that all veridical attitude verbs are question-embedding. The converse direction, as we will see, is more problematic, and it not obvious that all verbs that admit both thatcomplements and whether-complements should be factive. The aim of this paper, however, is to try and defend the hypothesis in its strong form, if only to see where it is most likely to break down. 
Before we proceed, I want to make the caveat that this paper is fundamentally on the link between that-complements and whether-complements, rather than on wh-complements in general. To be more precise, what I want to examine is to what extent factivity can be seen as necessary and sufficient in order for a verb that takes that-complements to take whether-complements. The restriction to whethercomplements has to do with the fact that some verbs that do not licence whethercomplements do seem to licence wh-complements. This happens with emotive predicates like surprise, and even with verbs like believe and regret in appropriate contexts: ${ }^{1}$

(3) Peter will never believe who came to the party

(4) Peter was surprised by who came to the party

(5) Peter really regrets who came to the party

Not all native speakers of English find (4) and (5) completely acceptable, but for some of them these sentences are fine. On the other hand, for both kinds of speakers the same contexts clearly rule out the embedding of whether-complements:

(6) *Peter will never believe whether Mary came to the party

(7) *Peter was surprised by whether Mary came to the party

(8) *Peter really regrets whether Mary came to the party

In what follows, we will refer to whether-complements as the basic test for question-embedding, setting aside the explanation of why verbs like surprise are nevertheless able to licence wh-complements. ${ }^{2}$

The paper is structured as follows. In Section 2, I first discuss three different accounts of the impossibility of embedding whether-complements after believe, namely the accounts of Zuber (1982), Ginzburg (1995) and Saebo (2006). As we will see, all accounts make direct or indirect use of the notion of factivity to explain why believe, in particular, fails to embed questions. None of those, however, explains why factive verbs would embed questions in the first place. In section 3, I make a different proposal to derive the generalization that all veridical attitude verbs embed questions. Section 4 examines the converse of the generalization, namely the case of non-veridical verbs that are question-embedding (like tell, decide, agree on).

\footnotetext{
${ }^{1}$ See Lahiri (2002) for a discussion of whether wh-complements should be seen as questions (rather than free relatives, or exclamatives) after such verbs.

${ }^{2}$ See Saebo 2006 for a recent discussion of whether-complements after surprise. One of Saebo's examples is particularly intriguing, namely "Don't read this installment before seeing the episode if you want to be surprised at whether or not Hercules makes it" (example (25) in Saebo's paper). Saebo uses the example to argue that the exclusion of whether-complements after surprise is pragmatic, and not syntactic or semantic. We may note, however, that a sentence like "You will be surprised whether or not Hercules makes it" is not acceptable.
} 


\section{Facts and Factivity}

In this section I compare three different accounts of the distribution of that- and whether-complements among attitude verbs. I start with the examination of a little known note by Zuber 1982, and go on to examine Ginzburg's 1995 theory, and the pragmatic account recently put forward by Saebo 2006. In all of these theories, we will see that the notion of factivity plays an explanatory role, but only indirectly. In particular, none of these theories explains why factive verbs should embed questions in the first place.

\subsection{Neg-Raising and Factivity (Zuber 1982)}

In a brief note, Zuber observed that neg-raising verbs cannot take whethercomplements, and proposed to explain this failure on the basis of their neg-raising behavior. Believe, in particular, is neg-raising, which means that a sentence of the form " $x$ does not believe that $p$ ", where negation takes wide scope over the verb, can be used to mean the stronger " $x$ believes that not $p$ ", in which the verb raises above negation:

(9) Mary does not believe that it will rain $\rightarrow$ Mary believes that it will not rain

A verb like believe clearly differs from know in this respect, since for know that inference is not available:

(10) Mary does not know that it will rain $\nrightarrow$ Mary knows that it will not rain

The inference associated to neg-raising is not usually considered to be a semantic entailment, but rather a pragmatic inference of some sort (see Gajewski 2005 in particular, who handles neg-raising as an inference based on a cancellable presupposition of the verb). Zuber does not say what he takes the status of the inference to be, but he basically handles it as a semantic entailment for the purpose of his argument.

Zuber's explanation makes further assumptions about the semantic behavior of whether-complements. In particular, Zuber assumes that for any verb $V$ that takes both that- and whether-complements:

$$
\text { " } V \text { that p" implies " } V \text { whether } \mathrm{p} \text { " }(V p \rightarrow V ? p)
$$

and likewise:

(b) "not $V$ that p" implies "not $V$ whether $p$ " $(\neg V p \rightarrow \neg V ? p)$

In particular, both inferences appear to be satisfied with a verb like know:

(11) Pierre knows that it is raining $\rightarrow$ Pierre knows whether it is raining

(12) Pierre does not know that it is raining $\rightarrow$ Pierre does not know whether it is raining 
Zuber's argument proceeds by reductio to show that if believe whether was a grammatical construction, this would conflict with the neg-raising behavior of believe, based on the assumptions about the behavior of whether-complements. Thus one would have:

$$
\begin{array}{llll}
\text { (1) } & \neg B p \rightarrow B \neg p & & \text { (neg-raising) } \\
\text { (2) } & B \neg p \rightarrow B ? p & & \text { (from (a)) } \\
\text { (3) } & \neg B p \rightarrow B ? p & & \text { (from (1) and (2)) } \\
\text { (4) } & \neg B p \rightarrow \neg B ? p & & \text { (from (b)) } \\
\text { (5) } & \neg B p \rightarrow B ? p \wedge \neg B ? p & & \text { (from (3) and (4)) }
\end{array}
$$

The conclusion is that if "believe whether $p$ " was grammatical "Pierre does not believe whether $p$ " would be impossible to utter without contradiction.

Granting Zuber's premises, his account would explain why other neg-raising verbs, like want for instance, do not take whether-complements. On the other hand, we may note that his theory leaves unexplained why a verb like regret, which is not neg-raising, does not take whether-complements. This is not by itself an objection, of course, since for such a verb other mechanisms could very well come into play to explain the exclusion of whether-complements. More problematically, as pointed out by B. Spector, the account does not explain why a verb close in meaning to believe, like be convinced, cannot take whether-complements. The problem in that case is that a predicate like be convinced is not neg-raising:

John is not convinced that it is raining ( $\nrightarrow$ John is convinced that it is not raining)

(14) *John is convinced whether it is raining

Furthermore, the account does not make explicit on what basis one should expect whether-complements to satisfy properties (a) and (b) when embedded under any verb $V$. In particular, Zuber does not specify in his note what the meaning of whether-complements should be in general, nor the kind of implications that (a) and (b) should be. Clearly, however, the inference patterns (a) and (b) cannot both be simple semantic entailments, for this would predict that " $V$ that $\mathrm{p}$ " and "V whether $p$ " are semantically equivalent in general, which is not the case.

One possible way of deriving Zuber's constraints, which anticipates on the proposal we will make more explicit in Section 3.2 below, would be the following. Let us assume that "whether $p$ " denotes the true answer to the question whether $p$ (an assumption made by Karttunen 1977 as well as Groenendijk and Stokhof 1982), so that for any $V, V_{x} ? p$ is true in $i$ if $x$ is in the relation denoted by $V$ to the true answer to ? $p$ in $i$. Assume that $V$ is factive in the presuppositional sense, namely such that $V_{x} p$ is defined in $i$ provided $p$ is true in $i$. Then one can verify that $V$ will satisfy both properties (a) and (b). As for (a), if $V_{x} p$ is true in $i$, then $p(i)=1$, by factivity, and so $x$ is indeed in the relation to the true answer to the question whether $p$ in $i$, that is $V_{x} ? p$ holds in $i$. As regards (b), assume $\neg V_{x} p$ is true in $i$. Since $V$ is factive, this presupposes that $p(i)=1$, so $x$ fails to be in the 
relation denoted by $V$ to the true answer to whether $p$, and therefore $\neg V_{x} ? p$ holds too.

Thus, if $V$ is assumed to be factive, the constraints (a) and (b) are met. As observed by Kiparsky and Kiparsky 1970, furthermore, factivity (in the sense of presupposing the truth of the complement) appears to be incompatible with negraising: if $\neg V p$ presupposes that $p$ is true, then $\neg V p$ cannot be strengthened into $V \neg p$, for this would imply that $\neg p$ is true (see Gajewski 2005). What Zuber's theory ends up showing, under this interpretation of the constraints (a) and (b), is that if a neg-raising verb like believe were to pattern like a factive verb, then this would give rise to a contradiction.

At this point, however, one should ask whether the patterns (a) and (b) are always met with verbs that take both that-complements and whether-complements, and whether they only appear with factive verbs. Prima facie, it seems the patterns can be observed with a non-veridical question-embedding verb like say. Consider for instance:

$$
\begin{aligned}
& \text { John said that Mary had left } \\
& \text { John did not say that Mary had left }
\end{aligned}
$$

A sentence like (15) cannot easily be followed by: "but John did not really say whether Mary had left". It can be followed, however, by: "but John did not say the truth about whether Mary had left". If so, this suggests that the (a) constraint can be met even for non-veridical verbs, a point to which we will return in section 4 .

A sentence like (16), by contrast, is compatible with the continuation: "John said that Mary did not leave". This is enough to show that "John did not say that Mary had left" does not entail "John did not say whether Mary had left". However, it may be the case that by default a sentence like (16) implicates: "John did not say that Mary had not left". One way to derive the implicature is to observe that "John said that Mary had not left" is more informative than the actual utterance: "John did not say that Mary had left" (assuming John does not contradict himself). Assuming a Gricean reasoning where the two sentences would stand as alternatives, an informed speaker who utters the latter implicates the negation of the former sentence, namely "John did not say that Mary had not left". The conjunction of the two sentences, finally, namely "John did not say that Mary left and John did not say that Mary had not left", seems equivalent to: "John did not say whether Mary had left".

Another way of deriving Zuber's constraints, consequently, could be to assume that $V ? p$ means $V p \vee V \neg p$. On that interpretation of the meaning of whethercomplements, the constraint (a) is automatically met, since $V p$ trivially implies $V p \vee V \neg p .^{3}$ But then, the entire weight of the explanation rests on condition (b),

\footnotetext{
${ }^{3}$ An alternative account of the infelicity of "believe whether $p$ " sentences, also based on negraising, would consist to assume, as Gajewski 2005, that neg-raising originates from the idea that believe presupposes opinionatedness on the part of the attitude-holder. Thus, "John does not believe that $p$ " should presuppose that either John believes $p$ or that he believes not $p$; consequently, this
} 
which, as we see here, turns out to be an implicature for a non-veridical verb like say. Under either of the proposed derivations of Zuber's constraints, we conclude that the inferential status of the constraint (b) above is not clear. As such, therefore, the account is not empirically adequate, nor sufficiently grounded.

\subsection{Facts and Propositions (Ginzburg 1995)}

The second account of question-embedding we shall examine in this section, Ginzburg's 1995 account, rests on the assumption that the crucial feature of factive verbs is that they express a relation to a fact, and that the notion of fact ought to be taken as a primitive.

According to a tradition that goes back to Russell 1918, the semantic distinction between a verb like know and a verb like believe has to do with the fact that knowledge expresses a relation between an agent and a fact, while believe only expresses a relation between an agent and a proposition. Thus, Russell (1918: 93) writes: "I am inclined to think that perception, as opposed to belief, does go straight to the fact and not through the proposition. When you perceive the fact you do not, of course, have error coming in, because the moment it is a fact that is your object error is excluded.(...) Therefore, the logical form of perception will be different from the logical form of believing, just because of that circumstance that it is a fact that comes in". While Russell talks only about perception in this quote, his account can readily be extended to knowledge. The central aspect of the opposition between facts and true propositions, finally, is that facts are conceived as irreducible to true propositions (see Kratzer 2002 and Holton 2006 for more about facts).

Following Russell, Vendler (1972: 105) makes the claim that "that"-clauses are ambiguous, depending on the kind of verb under which they appear. ${ }^{4}$ Vendler's thesis that belief and knowledge are attitude toward distinct types of entities is based on several linguistic contrasts, which include, in particular, the evidence that

is taken to imply that he believes $\neg p$. Assuming a weak semantics of "whether $p$ " whereby " $V ? p$ " would mean: " $V p \vee V \neg p$ ", then "believe whether $p$ " would end up making a vacuous assertion, since it would only assert what the use of believe presupposes. As pointed out to me by B. Spector, however, again an account like this does not generalize in any obvious way to be convinced whether, since be convinced does not satisfy the presupposition that the subject is convinced that $p$, or convinced of $\neg p$.

${ }^{4}$ The idea that that-clauses are ambiguous is also defended by Kiparsky and Kiparsky 1970, who contrast "regret that" and "believe that" sentences. They notice that "I regret that John is ill" licences "I regret the fact that John is ill", while "I believe that John is ill" cannot be expressed as "*I believe the fact that John is ill". According to them, "Simple that-clauses are ambiguous, and constitute the point of overlap (neutralization) of the factive and non-factive paradigm" (1970: 356). Surprisingly, however, Kiparsky and Kiparsky do not compare "know" and "believe". But although know is factive, "I know the fact that it is raining" is not quite felicitous to mean "I know that it is raining". Another difference between that-complements after regret and after believe or know concerns the fact that the complementizer "that" cannot be omitted after "regret". Thus: "*John regrets it is raining" is incorrect, as opposed to "John knows/believes it is raining" (I am indebted to Lea Nash for this observation). For all these reasons, the contrasts that Kiparsky and Kiparsky have between regret and believe are not necessarily relevant when one compares know and believe. 
believe, unlike know, does not select questions as its complements. Vendler points out two other sets of contrastive data, which are worth reminding here. The first of these, originally put forward by Austin 1954, concerns the opposition between why- and how-questions. Questions concerning the justification of belief are typically why-questions, while questions concerning the justification of knowledge are typically how-questions:

a. Why do you believe that it is raining?

b. *How do you believe that it is raining?

a. *Why do you know that it is raining?

b. How do you know that it is raining?

The second contrast concerns the behavior of know and believe with respect to what-clauses (to the extent that they are questions at all in the relevant contexts). Thus, it is possible to say:

\section{Mary knows what Peter said}

Mary believes what Peter said

If Peter said "it is raining", then from (20) one can only infer that Mary believes that it is raining. From (19), however, it does not necessarily follow that Mary knows that it is raining (she may think Peter said something false). More precisely, what (19) typically means is: "Mary knows that Peter said that it is raining". No such interpretation is available with "believe" in (20), however. ${ }^{5}$

None of these contrasts, we should note, provides clear linguistic evidence for the idea that "that"-clauses are ambiguous. Ginzburg, however, adds to Vendler's data some tests involving the nominalization of that-clauses. Thus, from "Peter believes that it is raining", one can infer "Peter believes a certain hypothesis". By contrast, from "Peter knows that it is raining", one cannot infer in the same way: "Peter knows a certain hypothesis". This suggests that the complement of know and the complement of believe fall in distinct categories.

Vendler's claim that "that"-clauses are ambiguous plays a central role in Ginzburg's 1995 theory of question-embedding. Thus, Ginzburg proposes a classification of attitude verbs into three main classes, depending on the kind of objects denoted by their complements. In Ginzburg's formal ontology, questions, propositions and facts correspond to three distinct kinds of entities. Accordingly, attitude verbs are divided in three main categories, namely resolutive verbs (such as know, and also tell), which can take facts in their denotation and licence both that and whcomplements; interrogative verbs (such as wonder), which take questions in their denotation, and only allow wh-complements; and truth-falsity verbs, namely verbs

\footnotetext{
${ }^{5}$ In (20), the what-clause is obviously a free relative, and not an interrogative complement. In (19), the what-clause can be both a free relative, or a question, namely "What did Peter say". If questions are prohibited after "believe", then the contrast can easily be accounted for. I am indebted to P. Schlenker for this observation.
} 
of assertion and opinion such as believe, which only allow that-complements.

On Ginzburg's theory, an attitude verb that takes that-complements can take interrogative complements if and only if it expresses a relation to a fact. In order to explain why believe cannot take questions, Ginzburg postulates that a question can be coerced to a fact, but can never be coerced to a proposition. The technical notion of coercion, introduced by J. Pustejovski, can be grasped informally in the following way: to say that a question can be coerced into a fact means that the question-denoting complement can be expressed in terms of a fact-denoting complement. ${ }^{6}$ For instance, to know whether Mary left is to know the fact that Mary left if she did, or to know the fact that Mary did not leave if she did not.

The class of resolutive verbs, finally, is divided into two classes, namely resolutive factive verbs, like know, and resolutive non-factive verbs, like tell. An important point about tell is that tell can embed questions, despite the fact that it is not factive with respect to that-complements. On Ginzburg's account, however, tell does express a relation to a fact whenever it also expresses a relation to a question. In that, Ginzburg follows the remarks of Baker (1968), who pointed out that "John told Mary who left" is typically judged false in a situation in which John made a mistake or gave some false information about who left. Thus resolutive non-factive verbs are ambiguous, since unlike believe, they can express relations to propositions or to facts.

In comparison to the account discussed in the previous section, Ginzburg's account makes a clear connection between factivity and question-embedding. It is unclear, however, to what extent the account is really explanatory, since Ginzburg only stipulates that questions can be coerced into facts, and cannot be coerced into propositions. Lahiri points out two further limitations of the account (Lahiri 2002: 290-91). The first concerns the case of regret. Using one of Ginzburg's nominalization tests, it seems one can infer "Peter regrets the fact that it is raining" from "Peter regrets that it is raining". Prima facie, this suggests that regret denotes a relation to facts, yet regret does not embed questions. Another objection concerns the behavior of predicates like agree (on), which are not factive with respect to that-complements, and which are not veridical either with respect to interrogative complements. For instance:

a. Jack and Mary agree that Peter left

b. Jack and Mary agree on whether someone left

For (21)a to be true, Jack and Mary need only agree on the truth of a proposition (the proposition that Peter left), which may perfectly turn out to be false. Clearly, however, (21)a entails (21)b, and on Ginzburg's account the complement of the preposition "on", namely "whether someone left" denotes a question (Lahiri 2002: 290). As such, therefore, a verb like agree threatens the generalization whereby

\footnotetext{
${ }^{6}$ See Pustejovsky 1993: 83, who defines type coercion as "a semantic operation that converts an argument to the type which is expected by a function, where it would otherwise result in a type error".
} 
questions cannot be coerced into propositions.

\subsection{A pragmatic account (Saebo 2006)}

In a recent paper Saebo presents a pragmatic account of the exclusion of whethercomplements after believe. The presupposition of factivity associated to know also plays a central role in the explanation, but the main aspect of Saebo's account is the idea that know and believe are competing alternatives, and that a sentence like "Peter believes whether it is raining", if it could be uttered, should be systematically dispreferred to a sentence like "Peter knows whether it is raining".

Saebo's account is presented in the framework of bidirectional optimality theory, but makes use of general principles of the theory of implicatures and presuppositions. More precisely, Saebo's theory is based on an account of the competition between believe and know in front of that-complements, which he generalizes to the case of whether-complements. To use an example from Sauerland (2007), from a sentence like:

John believes that 313 is a prime.

one typically infers that the speaker does not believe that 313 is a prime. One way to account for this inference is to notice that if "313 is a prime" was believed by the speaker, it would be more appropriate for her to say "John knows that 313 is a prime". Saebo presents the inference as based on the Gricean Maxim of Quantity ("make your contribution as informative as possible"). As Sauerland (2007:7) argues for this and related phenomena, it is even more adequate to talk about a principle of maximization of presuppositions, as first formulated by Heim 1991, namely "Make your contribution presuppose as much as possible!". Indeed, in a case in which the speaker takes it to be part of the common ground that 313 is a prime, a sentence like (22) would be misleading. In Saebo's framework, the sentence "John believes that $\phi$ " is likewise predicted to be less optimal than "John knows that $\phi$ " in all contexts in which $\phi$ follows from the common ground, namely in all contexts in which the presupposition of know is satisfied. Conversely "John believes that $\phi$ " will be more optimal than "John knows that $\phi$ " in all contexts in which $\phi$ does not follow from the common ground, since the presupposition is not satisfied for know. Thus, Saebo predicts that any sentence of the form "John believes that $p$ " will implicate that $p$ does not follow from the common ground. For future reference I call this implicature the "BT-implicature" (for "Believe That"):

BT-implicature: a sentence of the form "John believes that $\phi$ " implicates that the that-clause $\phi$ does not follow from the common ground.

In the case of whether-complements, Saebo postulates that a similar implicature should hold in principle. His account goes on to show that if a sentence of the form "John believes whether $\phi$ " could be uttered, then it should implicate in the same way that the presupposition associated to "John knows whether $\phi$ " does not hold. On his theory, however, the presupposition of "John knows whether $\phi$ " 
turns out to be a tautology, and holds vacuously. From this, it follows that a sentence like "John believes whether 313 is a prime" would implicate a contradiction, which explains why the sentence is blocked.

The way Saebo derives this result is by assuming that any sentence of the form "John knows $\psi$ " (where $\psi$ is either of the form "that $\phi$ or "whether $\phi$ ") is defined only if the proposition $\lambda i \psi(i)$ (which he calls the rectified complement proposition or RCP) follows from the common ground. When $\psi$ is a that-clause, namely of the form $\psi=\lambda w(\phi(w)=1)$, then the RCP $\lambda i \psi(i)$ reduces to $\lambda i(\phi(i)=1)$, which corresponds to the denotation of the that-clause. When $\psi$ is a whether-clause, taken to be of the form $\lambda w(\phi(w)=\phi(i))$ (Groenendijk \& Stokhof 1982), the RCP $\lambda i \psi(i)$ reduces to $\lambda i(\phi(i)=\phi(i))$, namely to a tautology. The BT-implicature associated to believe-that sentences is then generalized by Saebo into a generalized implicature for believe-that and believe-whether complements alike (we shall call it the BRCP-implicature):

BRCP-implicature A sentence of the form "John believes $\psi$ " implicates that the RCP $\lambda i \psi(i)$ does not follow from the common ground

From this assumption it follows that when $\psi$ is a that-clause, what is implicated is that $\psi$ does not follow from the common ground, which yields the BT-implicature. When $\psi$ is a whether-clause, on the other hand, what is implicated is a contradiction, since any tautology necessarily follows from the common ground, and this should explain why "believe whether" is not grammatical.

As we can see, Saebo's account of the infelicity of whether-complements after believe does not depend directly on its non-factive behavior, but more centrally, on the competition with know. The factivity of know, on the other hand, is needed to explain the BT-implicature of believe, which Saebo generalizes to the case of whether-complements.

One possible objection concerns the order of explanation in Saebo's account. In the case of the BT-implicature, one derives the existence of this implicature, based on the fact that a sentence of the form "X believes that $p$ " was actually uttered, and on the principle of maximization of presuppositions. In other words, an implicature is derived from the competition between two sentences that can both actually be uttered. For the generalization to whether-complements, however, there is no evidence that any implicature should take place in principle, other than by analogy with the case of that-complements.

A second issue about Saebo's account concerns the way in which it can be generalized. For the case of a verb like surprise, in particular, Saebo suggests that the exclusion of whether-complements is based on a competition between that-clauses and whether-clauses (rather than between alternative matrix verbs), in relation to the factivity of the verb. If we consider a verb like regret (which is closely related to emotives like "be surprised", "be sorry" or "be sad"), Saebo's account should predict that "John regrets that $\phi$ " is strongly optimal over "John regrets whether $\phi$ " whenever $\phi$ follows from the common ground, due to the factivity of regret. In the same way, his account will predict that "John knows that $\phi$ " is strongly opti- 
mal over "John knows whether $\phi$ " whenever $\phi$ follows from the common ground. This prediction is correct, since for instance "John knows that Mary left" is clearly more informative that "John knows whether Mary left" in a situation in which it is part of the common ground that Mary left. But then, how can it be explained that "know whether" is nevertheless a grammatical form, while "regret whether" is systematically excluded?

To account for the difference, Saebo observes that the use of a predicate like surprise generally bears a stronger factivity presupposition than the use of know in front of wh-complements. One can say "John knows who left" without knowing who left ("John knows who left, let us ask him"). By contrast, according to Saebo, "John was surprised by who left" tends to convey that the speaker knows who left. Saebo calls this feature super-factivity. Independently, Guerzoni (2007) also makes use of a related notion of speaker-factivity, on the basis of similar examples. The difference between factivity and super-factivity is in fact crucial to explain why "be surprised whether" is less optimal that "be surprised that", since according to Saebo the only relevant contexts that would occur for the evaluation of "Mary is surprised whether it is raining", for instance, should be contexts in which either the speaker knows that it is raining, or contexts in which the speaker knows that it is not raining (by speaker-factivity). By application of the principle of maximization of presuppositions, the speaker should therefore prefer to use "Mary is surprised that it is raining" or "Mary is surprised that it is not raining" each time. The situation is supposed to be different with "John know whether it is raining", since that sentence becomes optimal in a situation in which the speaker herself does not know which of "it is raining" or "it is not raining" is true (in that case, the use of the thatcomplement is simply impossible).

Despite this and notwithstanding the convergence between Saebo's and Guerzoni's intuitions, the notion of super-factivity is not completely clear. For instance, it seems one can say:

(23) I met John this morning. He was very surprised by who had failed the exam in his class. I did not dare ask him which students had failed, but he seemed to be really disappointed.

Clearly, the sentence "I did not dare ask which students had failed" conveys that the speaker does not know who failed the exam. This casts doubt on the robustness of the notion of super-factivity. As a result, the explanation of the exclusion of whether-complements after emotive verbs like be surprised or regret remains inconclusive. If regret is simply factive, and not super-factive, then some other mechanism must be used to explain the difference with know with regard to whether-complements.

\subsection{Summary}

Saebo's theory of the exclusion of whether-complements is explicitly presented as a pragmatic, rather than syntactic or semantic. As we saw, his account appeals 
to two kinds of competition (between complementizers on the one hand, and between matrix verbs on the other hand, depending on the verbs). This, however, may also be issue, if one can give evidence that the exclusion of whether-complements after believe and regret might be based on one uniform mechanism, rather than on different mechanisms. While more directly semantic, we saw that Zuber does not account for the exclusion of whether-complements after regret, which is not neg-raising. Likewise, Ginzburg's account does not make clear why the complements of regret, if they are facts, do not put regret on a par with know with respect to questions. All the accounts we reviewed, moreover, propose to explain why whether-complements are excluded in specific contexts, but they do not provide a positive account of the cases in which whether-complements are licenced by verbs that take that-complements. In the next section, I propose to see how Hintikka's factivity hypothesis may be justified to account both for the admission and for the exclusion of whether-complements. The way we will formulate the hypothesis will end up putting believe and regret in the same category.

\section{Veridicality and question-embedding}

In this section I present one way of deriving Hintikka's factivity hypothesis. ${ }^{7}$ More exactly, I examine one direction of the hypothesis, according to which all veridical attitude verbs are able to embed whether-complements. First, we need to say more about the difference between factivity and veridicality.

\subsection{Veridicality and Factivity}

We shall call a verb that takes that-clauses veridical if it entails the truth of its complement when used in the positive declarative form, namely if it satisfies the schema $V p \rightarrow p$ for all $p$, where $p$ is a "that"-clause. Following Kiparsky and Kiparsky 1970, we shall call a verb $V$ factive if asserting $V p$ presupposes the truth of the complement $p$. A verb like know is both factive and veridical, since "John knows that it is raining" implies that it is raining, but "John does not know that it is raining" also commits the speaker to the belief that it is raining. ${ }^{8}$ Some predicates

\footnotetext{
${ }^{7}$ I should note here that the account I propose is most likely not exactly what Hintikka had mind, nor does it purport to be. Hintikka 1975:21 only explicitly comments on "knowing who" constructions, as in "Dr Welby knows who has a pneumonia", which he analyzes as: $\forall x(P x \rightarrow$ Dr Welby knows that $P x)$. He writes that "on the universal-quantifier reading of subordinate whquestions the main verb ... receives a kind of success force, independently of whether it has one in the that-construction." His theory is that only verbs that already have this success force with thatcomplements can therefore enter in a wh-construction. Berman 1991 gives a more elaborate view of this account in terms of presupposition accommodation. I leave a discussion of Berman's proposal aside (see Lahiri 2002). To be completely fair to Hintikka's account, finally, I should note that his claim is that only factive verbs can embed questions, and does not explicitly say that all factive verbs should. Hence only verbs like tell, but not regret, are a putative counterexample to his account.

${ }^{8}$ Of course, it is always possible to say: "John can't know that it is raining, since it is not raining", but this is exactly a phenomenon of cancellation of the presupposition (also known as local
} 
like "it is clear", or "prove", appear to be veridical and yet not factive. Although the positive form of the verb entails the truth of the complement, this entailment is not preserved under negation, in particular:

(24) John has proved that Mary was not there that night [\# but in fact she was there]

(25) John has not proved that Mary was not there that night [and in fact she may have been there]

(26) It is clear that John is the one who did it [\# but John may not have done it]

(27) It is not clear that John is the one who did it [and in fact he may not have done it]

An important issue concerns the relation between the two notions of veridicality and factivity. One possibility is to see factivity as implying veridicality. Another is to see the two notions as independent in principle, albeit coinstantiated in some verbs. The choice between the two options matters, since it also depends on how one thinks factiveness presuppositions are generated. Usually, a factive predicate is considered ipso facto veridical, since factiveness is defined as preservation of the truth of the complement in specific contexts (viz. under negation, modals, and so on), but taking the positive context as the baseline.

In their grammar of the English Language, on the other hand, Huddleston and Pullum (2002) go for the second option. They call entailing the predicates we here call veridical, and consider that some verbs, like regret, admit, and resent, are factive but non-entailing. Usually, a verb like regret is presented as a paradigm case of factive verb, since from "John regrets that Mary left him", one infers that the speaker believes that Mary left John, and likewise for "John does not regret that Mary left him" (Kiparsky \& Kiparsky 1970, Karttunen 1971). Several examples, first put forward by E. Klein (1975), challenge the idea that regret (and other emotive predicates like "be glad") is really veridical:

(28) Falsely believing that he had inflicted a fatal wound, Oedipus regretted killing the stranger on the road to Thebes (Klein 1975, quoted in Gazdar 1979: 122)

(29) Ed believed that he had offended his parents and very much regretted that he had done so, but it turned out that he had been mistaken: they had not in the least been offended. (Huddleston and Pullum 2002: 1007)

(30) John wrongly believes that Mary got married, and he regrets that she is no longer single. (Egré 2004, 2005, based on Schlenker 2005, fn. 14)

One issue raised by such examples is whether the use of regret could possibly be a scare-quote use, as in a sentence like "Before Copernicus, people knew that the sun was revolving around the earth", in which the verb "knew" is usually given

accommodation). 
a special intonation indicating pretense on the part of the speaker. According to Gazdar (1979), examples similar to (28) are found with cognitive factive verbs, for instance:

(31) Falsely believing that he had inflicted a fatal wound, Oedipus became aware that he was a murderer.

A sentence like (31) appears to be a case of free indirect speech, whereby Oedipus is in fact saying to himself: "I am a murderer". Gazdar concludes from the parallel with (28), in particular, that Klein's examples do not provide "sufficient grounds for arguing that some or all factive verbs do not entail their complements" (1979: 123). Likewise, one may argue that sentences (28)-(30) also involve free indirect speech, by expressing in the that-clause the content of what the attitude holder would express directly by saying, for instance: "I regret that Mary got married".

One difference which remains, however, is that the substitution of "know" to "regret" in a sentence like (30) produces a contradiction. Thus, it seems just inconsistent to utter:

(??) John wrongly believes that Mary got Married and he knows that she is no longer single.

This suggests, at any rate, that know and regret do not behave in exactly parallel ways. In (30), it seems one can ascribe to John a true mental state of regret. In the case of (32), one cannot ascribe true knowledge in the same way.

Further elements suggest that regret and other emotive predicates, like be sad or even be surprised, may be closer to believe than to know (Schlenker 2005, Egré $2004,2005)$. One indication concerns the mood of the embedded complement in French. In French, emotive predicates like être triste (be sad) and être surpris (be surprised) require the verb of the that-clause to be in the subjunctive, like regretter (regret), in contradistinction to savoir (know), which selects for the indicative:

a. Pierre est surpris que Marie soit partie sans dire au revoir Pierre is surprised that Marie be SUBJ left without saying good bye.

b. *Pierre est surpris que Marie est partie sans dire au revoir. Pierre is surprised that Marie left $t_{I N D}$ without saying good bye.

a. Pierre sait que Marie est partie sans dire au revoir Pierre knows that Marie is IND left without saying good bye.

b. *Pierre sait que Marie soit partie sans dire au revoir. Pierre knows that Marie left $t_{S U B J}$ without saying good bye.

Contrary to (34)-a, a sentence like (33)-a does not necessarily imply that Pierre knows that Marie left without saying good bye, not even that the speaker assumes that Marie left without saying good bye. What the sentence presupposes is that it seems (at least to some participants in the conversation) that Marie left without saying good bye. The best way to approach the correct meaning would be to say 
that "Pierre is surprised that Mary might have left without saying good bye". Thus (33) can very well be pursed with:

(35) Moi aussi cela me surprend. A mon avis, elle a dû lui dire au revoir, mais il ne s'en souvient pas

It surprises me too. In my opinion, she must have said good bye to him, but he does not remember.

In what follows we shall therefore consider that regret, like other emotive predicates, and despite appearances to the contrary, is not veridical, unlike know. ${ }^{9}$ Following Huddleston and Pullum's grammar, one may still call regret a factive verb, bearing in mind the idea that the default interpretation of a sentence of the form "X regrets that $p$ ", in most contexts, including in questions and under negation, is that $p$ is true. To say this, however, is to commit oneself to a pragmatic understanding of the notion of factiveness (as opposed to a lexical one, whereby factiveness would be conceived as veridical entailment preserved in different contexts). ${ }^{10}$ According to Huddleston and Pullum, for instance, "just as one cannot regret some proposition $p$ unless one believes that $p$ is true, so one would not normally ask whether someone else regrets that $p$ unless one believes that $p$ is true" (2002: 1008). While this intuition seems plausible, it is clear that some principle about presupposition accommodation is needed to account for the inference from the lexical presupposition " $\mathrm{X}$ believes $p$ " associated to " $\mathrm{X}$ regrets $p$ " to the conclusion: "The speaker believes $p$ ". ${ }^{11}$

I will set aside a further discussion of this problem here. What matters for the present account is the idea that veridicality may indeed correlate better with

\footnotetext{
${ }^{9}$ Another observation on the contrast between know and regret can be seen by applying Vendler's tests. The why vs. how-questions suggests that regret behaves more clearly like believe than know in "Why do you regret that Mary left?", which is correct, as opposed to "*How do you regret that Mary left?". Using Vendler's own standards, this should mean that the objects of regret are more likely to be propositions than facts.

${ }^{10}$ See Gazdar 1979: 120, who describes Karttunen's position along the same line: "some writers, such as Karttunen, who have embraced a pragmatic definition of presupposition, seem implicitly to have abandoned the entailment relation between affirmative sentences and their presuppositions". Gazdar adds in a footnote (fn. 12) that "In fact, Karttunen (p.c. 1977) thinks that cognitive factives like know do entail their complements, but he is agnostic with respect to emotive factives like regret".

${ }^{11}$ To some extent, the problem bears some analogy to the proviso problem for presuppositions, originally put forward by B. Geurts (I am indebted to P. Schlenker, B. Spector, and D. Fox and R. Singh for pointing out this analogy). The proviso problem is that a conditional sentence of the form "if Theo likes sonnets, so does his wife" is predicted to semantically presuppose that if Theo likes sonnets, Theo has a wife. The presupposition accommodated in out of the blue contexts is the stronger presupposition that Theo has a wife. Heim 1992: 206 discusses another accommodation problem concerning sentences like: "John believes that it stopped raining", where we standardly accommodate "it had rained", rather than the predicted presupposition: "John believed that it had rained". The problem here is to figure out how we are able to infer: "it had rained" from "John believed it had rained". As such the problem is even more similar to what happens with "John regrets that it is raining", assuming that "John believes it is raining" is the presupposition, and that "it is raining" is what we accommodate. (Thanks to B. Spector and K. von Fintel for bringing Heim's example to my attention).
} 
question-embedding than factivity. In particular, veridical non-factive predicates like "prove" and "it is clear" can embed whether-questions:

As yet, there is probably no evidence that would definitively prove whether or not some dinosaurs were warm-blooded.

It is not yet clear whether such phenomena can be observed in patients with non-tumor diseases.

We may note that for such verbs, not all contexts allow for felicitous whetherembedding. For instance, in a context in which the speaker knows what John has proved about dinosaurs, it is obviously odd to say:

John has proved whether dinosaurs were warm blooded

Rather, one would expect the speaker to use "prove that", followed by the appropriate answer to the question. Likewise, in a context in which the speaker knows whether Mary left or not, it sounds incorrect to say:

It is clear whether Mary left.

Here again, one would expect "it is clear that" to be preferred by the speaker, unless the speaker wants to hide the information from the hearer, or signal to the hearer that he has an answer (like in: "it is completely clear to me whether Mary left, but I won't tell you, you need to find out for yourself"). For such cases, therefore, the infelicity of using "whether" is readily explained by the competition with "that"complements, exactly along the lines of Saebo's pragmatic account. But it remains that such verbs can embed whether-complements in principle, as opposed to verbs like believe or regret, which seem to exclude them completely.

\subsection{From veridicality to whether-embedding}

Assuming veridicality might be a necessary and sufficient condition for a verb that takes that-complements to take whether-complements, let us now try to derive this connection more formally. To do this, we need to specify what the meaning of whether-complements is, and what we should expect the meaning of a sentence of the form " $\mathrm{X} \mathrm{V}$ whether $p$ " to be in general.

In principle the meaning of embedded questions could very well depend on the embedding verb. For instance, it is not obvious that "whether $p$ " has the same meaning in "wonder whether $p$ ", "decide whether $p$ ", and "know whether $p$ ", a point to which we will return below. Here we shall assume that the meaning of "whether $p$ " is uniform, and that it denotes the true answer to the question whether $p$. More precisely, we assume Groenendijk and Stokhof's denotation for questions (Groenendijk and Stokhof 1982, 1990). In their framework, "whether $p$ " denotes the proposition that $p$ if $p$ is true, and that not $p$ if $p$ is false. More formally, $\llbracket$ whether $p \rrbracket(i)=\lambda w(p(w)=1)$ if $p(i)=1$, and 【 whether $p \rrbracket(i)=\lambda w(p(w)=0)$ if $p(i)=0$, that is $\llbracket$ whether $p \rrbracket(i)=\lambda w(p(w)=p(i))$. 
The expression $\lambda w(p(w)=p(i))$ corresponds to what GS call the extension of the question whether $p$. On GS's account, "whether $p$ " can also denote the intension of the question, for instance after wonder, namely the function that, in each context, gives the true propositional answer to whether $p$ in that context $(\lambda i \lambda w(p(i)=p(w)))$. By contrast, "whether $p$ " denotes the extension of the question after know, namely $\lambda w(p(w)=p(i))$, assuming $i$ is the evaluation context. Thus, the difference between "whether $p$ " after wonder and after know is fundamentally a type distinction, which leaves the meaning of the embedded question essentially invariant. Our first, assumption, therefore, is that, for a verb $V$ that takes both declarative and interrogative complements, whether-complements denote the true answer to the corresponding question:

(40) Meaning of whether: for a verb V that takes that-clauses, "X V whether $p$ " is true in $i$ iff the referent of $\mathrm{X}$ is in the relation denoted by $\mathrm{V}$ to the true answer to the question "? $p$ " in $i$.

Our next assumption about the meaning of "whether"-clauses is that they systematically weaken the meaning of "that"-clauses when embedded after verbs that admit both kinds of complements. This corresponds to Zuber's assumption (a), namely to the idea that all verbs that take both that- and whether-clauses satisfy the entailment from "that $p$ " to "whether $p$ ". For instance, one can check that the inference goes through for know and decide:
a. John knows that Mary left
b. John knows whether Mary left
a. John has decided that he will go to London
b. John has decided whether he will go to London

We call this second assumption the "that-to-whether" constraint:

that-to-whether constraint: a verb $\mathrm{V}$ that takes declarative complements takes whether-complements provided it satisfies the entailment from " $\mathrm{X} \mathrm{V}$ that $p$ " to " $\mathrm{X} \mathrm{V}$ whether $p$ ".

Now, it is easy to see that if a verb is veridical, then it systematically satisfies the that-to-whether constraint, given our assumption on the denotation of whethercomplements. Indeed, by definition, if a verb $V$ is veridical, then one has:

$$
\begin{array}{ll}
\text { a. } \quad \forall i[V(i)(a, \lambda w(p(w)=1)) & \rightarrow p(i)=1] \text { (veridicality), hence } \\
\text { b. } \quad \forall i[V(i)(a, \lambda w(p(w)=1)) \rightarrow V(i)(a, \lambda w(p(w)=p(i))]
\end{array}
$$

In other words, whenever a veridical verbs selects a that-clause, because the thatclause has to be true, it thereby corresponds to the extension of the corresponding whether-question.

For verbs that are not veridical, like believe or regret, on the other hand, the that-to-whether constraint cannot be satisfied in the same way. For instance, to 
believe that it is raining is to believe a proposition that could very well turn out to be false. Likewise, on the present account, to regret that it is raining does not by itself entail that it is raining. If $\mathrm{X}$ regrets that it is raining, $\mathrm{X}$ believes that it is raining and wishes it were not raining. But as we argued, X's regret can very well rest on a false belief.

\section{3 it is true that, be right that}

The constraint (43) is a stipulation of the theory, just like the assumption made above about the meaning of "whether". As stated, moreover, (43) may appear as only a sufficiency condition for question-embedding. For the condition to be fully explanatory, we need to suppose that if a verb does not automatically satisfy the entailment from "that" to "whether", then it does not licence whether-complements. Before turning to this problem, what we need to examine is whether, as a sufficiency condition, the condition does not already overgenerate. Some problem cases for the account here are non-factive predicates like "it is true that" and "be right that", which by definition entail the truth of their complement, and yet do not take whether-complements:

Mary is right that John left [\# but John did not leave]

*Mary is right whether John left

It is true that John left [\# but John did not leave]

One common aspect of these two predicates is that they are not attitude predicates per se. As Abusch (2002) observes about be right that, this predicate is in a sense symmetric to know, since "Mary is right that $p$ " asserts that $p$, and presupposes that Mary believes that $p$. Hence, stricto sensu "Mary is right that $p$ " does not assert that Mary believes that $p$, and to that extent it does not ascribe an attitude to Mary. By contrast, "Mary knows that $p$ " asserts that Mary believes $p$, and presupposes that $p$. Similarly, "it is true that it is raining" asserts that it is raining, but does not presuppose it. The same holds of the predicate "it is right that".

An important difference with predicates like "prove" or "be clear" is that "whether"-complements after prove or be clear, in the relevant contexts, ascribe a non-vacuous property to the true answer to the question. For instance:

(49) We will soon be able to prove whether some dinosaurs were warm-blooded

(50) By the end of the semester, it will be clear whether the budget was sufficient.

asserts that the true answer to the question will soon be proved. By contrast, sentences like "it is right whether it is raining", or "it is true whether is is raining" would assert that the true answer to the question is true/right, both of which being 
vacuous statements. ${ }^{12}$ Another way to see it is to look at the negation of "whether"sentences. "John does not know whether it is raining" says that the true answer to whether it is raining is not known to John, which is consistent without being trivial. But "it is not true/right whether it is raining" should mean that the true answer to the question is not true/right, which would then be contradictory.

This suggests that the correct way of putting the that-to-whether constraint is to say that a predicate $\mathrm{V}$ that takes that-complements takes whether-complements, provided the inference is non-vacuous. Alternatively, one may state this as a separate constraint, namely the constraint whereby an expression can appear as argument of another provided the resulting expression is non-vacuous. ${ }^{13}$

Finally, a predicate close to be right that is the predicate correctly believe that, which, by virtue of the adverb, is also veridical. In principle, our account should predict that such a predicate can take whether-complements, which is not the case:

Only 17 percent of Canadian adults correctly believe that $/ *$ whether approximately 45,000 Canadians die each year as a result of tobacco use

The embedding of "whether" after "correctly believe" is just as bad as under "believe". In this case one cannot say that the embedding of "whether" would be vacuous. Rather, the badness of the sentence obviously originates from the impossibility of embedding "whether"-complements after believe. This means that the that-to-whether constraint stated above cannot be taken to apply to arbitrary predicates, but only to the head of the verb phrase containing the that-clause ("correctly" is only an adjunct).

\subsection{Summary}

In this section we have given evidence in favor of the hypothesis that all veridical attitude verbs licence whether-complements. We have proposed to derive the generalization by assuming that whether-complements denote the corresponding true answer, and by observing that veridical attitude verbs, because of their veridical character, in principle allow to express that-clauses as whether-clauses in the positive form. Moreover, we have argued that emotive predicates like regret or be surprised should not count as veridical, despite the fact that in many contexts the truth of their complements is pragmatically presupposed. So far, however, we have said nothing about the converse direction of the factivity hypothesis. That is, while the present account predicts that all veridical attitude verbs licence whethercomplements, it leaves open the possibility for non-veridical verbs also to take whether-complements. The next section is devoted to this problem.

\footnotetext{
${ }^{12}$ Assume that $\llbracket$ True $\rrbracket(i)=\lambda P_{s t} T(i)(P)$, where $T(i)(P)=1$ iff $P(i)=1$. Then $\llbracket$ True $($ whether $p) \rrbracket(i)=T(i)(\lambda w(p(w)=p(i))=1$, since $\lambda w(p(w)=p(i))(i)=(p(i)=$ $p(i))=1$.

${ }^{13} \mathrm{I}$ here rely on unpublished remarks by J. Gajewski, and also D. Fox.
} 


\section{The case of non-veridical verbs}

We have formulated the that-to-whether constraint by saying that a verb which takes that-complements takes whether-complements provided it satisfies the entailment from " $V$ that $p$ " to " $V$ whether $p$ ". For the constraint to be fully explanatory, however, the constraint should be read as "if and only if". If so, this would explain not only why veridical verbs can take both that and whether-complements, but also why non-veridical verbs like believe and regret can not take whether-complements, since for such verbs the entailment is not satisfied.

One way of defending the biconditional formulation of the constraint is to observe that in all contexts in which " $V$ whether $p$ " is true, then if " $V$ that $p$ " is true, $p$ must be true too (given our semantics for whether). This, however, falls short of establishing that in all contexts in which " $V$ that $p$ " is true, $p$ should be true. In other words, it does not follow analytically that if a verb taking whether-complements is extensional in Groenendijk and Stokhof's sense, then it is veridical with respect to that-complements in all contexts. And indeed, counterexamples are given by verbs like tell, say, which are not veridical with respect to that-complements, but which admit whether-complements. Other problem cases for the present account include verbs like guess, but also doubt, agree (on), conjecture (about) and predicates like be certain (about) or be sure (on), which can all be followed by whether-clauses.

The first observation to make about such verbs, however, is that they fall in at least three different categories. As argued by Karttunen (1977b), whether-clauses after doubt are special and do not behave like questions, which sets doubt apart. Regarding the other verbs, we can see, following Lahiri 2002, that they fall into two distinct classes: most of the time, verbs like tell, say and guess appear to be veridical with respect to questions. By contrast, verbs like agree (on), be certain (about) are non-veridical with respect to questions. I examine these different verbs in turn. For the latter verbs, I argue that prepositions play a semantic role. Regarding the former, I argue that they are ambiguously veridical already with that-clauses.

\subsection{Doubt}

As discussed by Karttunen (1977b), whether-clauses after doubt behave idiosyncratically. In English the two sentences (52)-a and (52)-b can be used interchangeably:
a. I doubt that they serve breakfast
b. I doubt whether they serve breakfast

Karttunen also observes that doubt cannot take wh-questions ("*I doubt who is coming for dinner"), and does not licence alternative readings of disjunctive whether-questions ("I doubt whether they serve tea or coffee" can only mean "I doubt whether they serve either tea or coffee"). Moreover, "whether" cannot be replaced by "whether or not" after "doubt": 
*I doubt whether or not they serve breakfast

Karttunen therefore concludes that whether-clauses after doubt do not denote real questions. I concur with Karttunen's analysis here. One observation we may add to this is that in French, "douter si" is marginally acceptable and found in some dialects. In that case, however, the construction has a meaning close to "se demander si" (wonder), and it does allow for alternative readings and for "whether or not" constructions; moreover, "douter si" is followed by the indicative mood, unlike "douter que" (doubt that), which requires the subjunctive mood:

Les gens doutent si c'est la peste ou pas. (Google)

People doubt whether it is the plague or not.

(55) Nous voyons des gens qui doutent si l'univers n'est point l'effet du hasard ou d'une nécessité aveugle. (Google)

We see people who doubt whether the universe is not the effect of chance or of blind necessity.

(56) Les gens doutent que ce soit la peste / *que c'est la peste

People doubt that it be the plague / that it is the plague.

These data strengthen Karttunen's observation about English, since in French a sentence like "Pierre doute qu'il pleuve" (Pierre doubt that it is raining) cannot entail nor be expressed by "Pierre doute s'il pleut". We therefore agree with Karttunen that doubt does not embed whether-questions, exactly like believe.

\subsection{Tell, Guess and non-veridical readings}

While tell and agree both are non-veridical with respect to that-complements, one can observe that after tell or guess, embedded questions usually have a veridical reading, which means that the interrogative complement seems to denote the true answer to the question. For that reason, Lahiri (2002) puts them in the class of what he calls veridical responsive predicates. For instance:

John told Mary who was at the party

seems to mean that John told Mary the true complete answer to the question "who was at the party" (Baker 1968). ${ }^{14}$ In a situation in which only Sue and Bill were at the party, and John only told Mary that Sue was at the party, or told her mistakenly that Alfred was at the party, the sentence seems to be false. The same seems to hold of whether-questions. The sentence:

John will tell us whether it is raining in London.

conveys that John is expected to tell the true answer to the question. Likewise, guess in most contexts appears to force the veridical reading of the embedded ques-

\footnotetext{
${ }^{14}$ See also Holton 1996, who defends this view against counterexamples proposed by Tsohatzidis.
} 
tion:

John had guessed whether it would rain.

In such examples, tell seems to behave like reveal, which is factive with respect to that-complements, and likewise guess gets the meaning of the factive divine (cf. the French "deviner", which is factive with that-complements, and is one common way of translating "guess" in many contexts).

Interestingly, Lewis (1982) observed that "this veridical sense [of telling whether] may or may not be the only sense of 'tell whether'; it seems at least the most natural sense". At the same time, however, the remark indicates that Lewis had in mind the possibility of non-veridical readings of whether-complements after tell. Egré and Spector (2007) investigate the possibility that non-veridical readings of embedded questions might indeed exist after tell and other communication verbs (such as predict, or announce), on the basis of examples like:

(60) Everyday, the meteorologists tell the population whether it will rain the next day, but they are often wrong.

In such a case, it seems the meteorologists needn't tell the actual answer for the sentence "tell whether" to count as true. The hypothesis examined in Egré and Spector (2007) is that "tell whether $p$ " could then mean: to tell some potential complete answer to the question whether $p$, namely to tell $p$ or to tell $\neg p$, rather than to tell the actual answer to the question.

Further support for this idea also comes from the behavior of verbs of conjecture such as conjecture, guess, and predict:

(61) Out of all of the plays run on Saturday, I incorrectly guessed whether it was going to be a run or pass on just a handful.(Google)

(62) For each draw, I had to conjecture whether an odd number or an even number would come out. All my guesses proved to be wrong.

(63) In one study, $56 \%$ of recipients guessed incorrectly about an e-mail's intended tone, while $78 \%$ of the senders incorrectly predicted whether or not the recipients would get it right. (Google)

In (61) the verb guess seems to have exactly the meaning of predict, and ends up meaning: "I made an incorrect guess as to whether it was going to be a run or pass". Sentence (62) suggests that to conjecture whether $p$ would simply mean "to conjecture one of $p$ or $\neg p$ ", rather than "figure out the true answer". Due to the presence of "incorrectly", more generally, (61) and (63) seem to argue against Baker's idea that tell and guess allow only for veridical readings of embedded questions.

Such examples remain compatible with several interpretations, however. Lewis (1982), for instance, suggests that there may be a sense of "telling falsely whether" that "does not count as telling whether at all, but only as purporting to tell whether". 
Likewise, "conjecture whether" or "guess whether" might really mean "try to find out whether". This hypothesis seems adequate for a sentence like (60), but does not square well with an example like (61), however, where the verb "guessed" is modified by "incorrectly". If guess meant "try to make a correct guess", then one might expect the adverb "incorrectly", in "guessed incorrectly", to modify "try" semantically, which does not seem to get the correct meaning.

Another hypothesis, which we are about to see in the next section, is to view the non-veridical readings of questions after tell, guess and related verbs as parasitic on the veridical reading of the question, but as involving some coercion mechanism due to the presence of a preposition (possibly unexpressed). Such an account does not easily apply to tell or predict, however, for which no preposition seems ever to overtly show up. ${ }^{15}$

Setting aside a further discussion of these examples, I conclude that for the present account to be fully explanatory, we need to endorse the idea that tell is ambiguous between a factive and a non-factive interpretation already with thatclauses (see Egré and Spector 2007, and already Berman 1991, Ginzburg 1995). Furthermore, we are in principle committed to the view that questions after tell primarily have the veridical reading.

\subsection{Agree, be certain and the role of prepositions}

By contrast to verbs like tell or guess, verbs like agree or be certain are not only non-veridical with respect to that-complements, but also with respect to embedded questions. For instance, one can say:

a. Mary and John agree on who left

b. Mary and John agree on whether Sue left

a. John is certain about who left

b. John is certain on whether Sue left

In the first two examples, the object of Mary and John's agreement need not be the true answer to the question. It is enough for John and Mary, for instance, to agree that Sue left in order to agree on whether Sue left, even if in fact, Sue did not leave. The case is the same for (65-b): it is enough for John to be certain that Sue left in order for him to be certain on whether Sue left. Consequently, not only do such verbs licence both that- and whether-complements, but they appear to satisfy the that-to-whether constraint stated in (43) above. These verbs are a problem for the account spelt out in section 3 , since they are not-veridical.

From a syntactic point of view, however, these verbs clearly differ from the verbs we have discussed so far. For one thing, agree requires a preposition in front of embedded questions. In the case of be certain, the preposition can sometimes

\footnotetext{
${ }^{15}$ For instance, "John will tell us about whether Mary left" sounds odd, or otherwise has a meaning much weaker than "John will tell us whether Mary left" (see below).
} 
be dropped, but native speakers report that the sentences are not as good as when the preposition is expressed: ${ }^{16}$

(66) *John and Mary agree whether Sue left

(67) *John is certain whether Sue left

Another difference, observed by B. Spector, is that such verbs allow for the paraphrase "the question of whether". This is not so with know, for instance:

(68) *John knows the question of whether Mary left

(69) John and Mary agree on the question of whether Mary left

(70) John is certain about the question of whether Sue left

Interestingly, tell patterns like know relative to this test. By contrast, verbs like guess and conjecture allow for the presence of a preposition in contexts in which they give rise to an explicitly non-veridical reading of the embedded question:

(71) *John told Mary the question of whether Sue left

(72) For each draw, I had to conjecture about whether an odd number or an even number would come out.

(73) You'll never again have to guess about whether or not a plant needs water. (Google)

In (72) and (73), the presence of the preposition "about" clearly forces the verbs to mean "make a conjecture" and "make a guess" respectively. The interesting fact, in the light of our previous discussion, is that the sentences seem to retain the same meaning when the the preposition is not expressed. This is not so with know or tell, for which "tell about" and "know about", when they can be used, alter the meaning of the original sentence. For instance, the second sentence below conveys that John has some information relevant to answer the question, not necessarily that he knows the answer:

a. John knows whether Mary left.

b. John knows about whether Mary left.

Another verb, which appears not to be veridical, at least not in any obvious sense, is decide, which also embeds whether-complements and appears to satisfy the that-to-whether constraint:

a. John has decided that he will go to London

b. John has decided whether he will go to London

\footnotetext{
${ }^{16}$ The presence of a negation seems to help, as in "John is not certain whether Mary left", "John is unsure whether Mary left".
} 
While decide can have an epistemic reading in some contexts, it does not appear to be veridical. For instance, one can say:

(76) John had decided that he would go to London before Christmas. But he never went there.

As a consequence, to decide whether $p$ seems to mean simply "to decide $p$ or to decide $\neg p$ ", and not necessarily "to decide the true answer to the question whether $p$ " (meaning the true answer relative to the actual world). For decide too, however, it is possible to add the preposition "about" without altering the meaning of the sentence:

(77) John has decided about whether he will go to London

(78) John has decided about the question of whether he will go to London

One way of accounting for these contrasts is to see the preposition "about" as allowing both for such non-veridical verbs to embed questions, and as explaining the non-veridical interpretation of the questions in these contexts. Let us consider, for instance, the following valid inference:

a. John believes that Mary left

b. John has a belief about whether Mary left.

We may suppose that the first sentence gets translated to: $\operatorname{Bel}(j, L(m))$, where $L(m)$ is of type st and denotes $\lambda w(\llbracket L(m) \rrbracket(w)=1)$. The logical form of the second sentence can be taken to be: $\exists P_{s t}[(\operatorname{About}(? L(m)))(P) \wedge \operatorname{Bel}(j, P)]$. To account for the inference, we shall suppose that the sentence (79-b) is analyzed according to the following parse tree, where "John has a belief about whether Mary left" is analyzed as "John believes some proposition about whether Mary left":

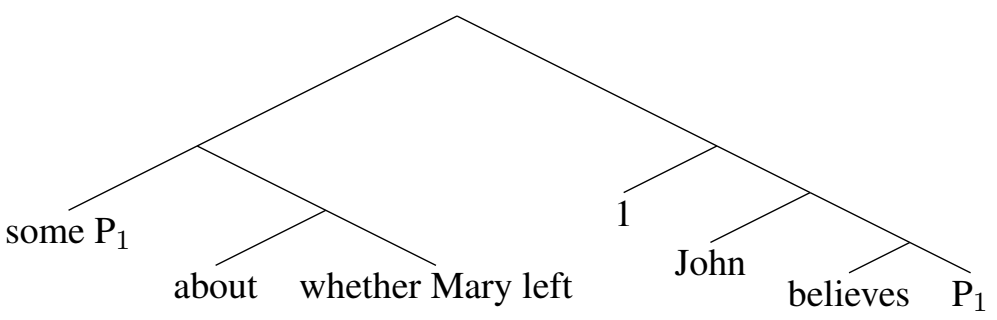

We assume the following semantics (following Heim and Kratzer's 1998 treatment of quantifier raising, where the DP moves and leaves a trace):

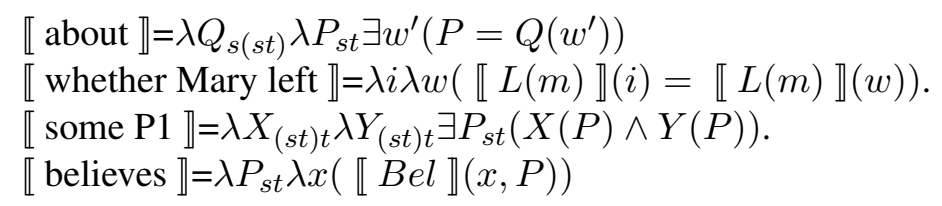

Applying the rules of functional application, one can check that the sentence is true if and only if: $\exists P_{s t}\left(\exists w^{\prime}\left(P=\lambda w\left(\llbracket L(m) \rrbracket\left(w^{\prime}\right)=\llbracket L(m) \rrbracket(w)\right) \wedge\right.\right.$ 
$\llbracket B e l \rrbracket(\llbracket j \rrbracket(P))$, namely if there is a proposition that is a potential answer to the question whether Mary left, and John believes that proposition. This analysis allows us to capture the inference in (79). Crucially, however, this inference no longer rests on the veridicality of the verb, but only on the semantics assumed for "about".

We can generalize this proposal to other verbs followed by a preposition like "about", such as agree, or decide. Adapting the previous tree, the proposed analysis for "John and Sue agree on whether Mary left" also yield there is some potential answer to the question of whether Mary left on which John and Sue agree:

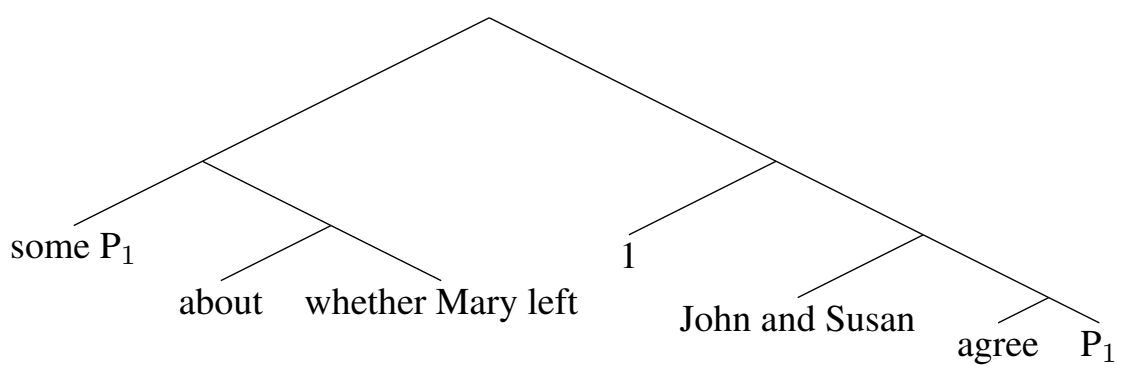

In these examples we assumed that for a proposition to be about a question, the proposition must correspond to some potential complete answer in Groenendijk and Karttunen's sense (as in Egré and Spector 2007). Arguably, this meaning for "about" may be too strong for embedded wh-questions after some predicates. For instance, in order to have a belief about who came, it is probably sufficient to believe a proposition that only partially answers the question (rather than a potential complete answer in GS's sense). ${ }^{17}$ For a verb like agree, on the other hand, the meaning assumed seems adequate, since in order to agree about who left, it is not enough to agree on some partial answer: John and Mary may agree that Sue left, bit disagree about Janet, for instance, in which case they disagree about who left.

\subsection{Summary}

In this section we have seen that verbs that question-embedding verbs that are nonveridical with respect to that-complements fall in two main categories, following Lahiri's 2002 typology (and setting aside the case of doubt, which turns out not to embed questions). For the verbs that Lahiri calls non-veridical responsive, like agree, our account relies in an essential way on the overt or covert presence of a preposition like "about". For that reason, such verbs cannot be taken to satisfy the that-to-whether constraint directly. For verbs like tell, which Lahiri classes as veridical with respect to questions, we have seen that we need to postulate a systematic ambiguity, and to assume that there is a veridical use of tell which allows

\footnotetext{
${ }^{17}$ A complete answer, in Groenendijk and Karttunen's sense, corresponds to a cell in the partition determined by the question. If John left and Mary didn't, and they are the only two individuals in the domain, the complete answer to "who left?" is "John left and Mary didn't". By contrast, "John left", "Mary didn't leave" count as partial answers. For whether-questions, partial answers happen to be complete answers however.
} 
for whether-embedding. As we have seen, however, the data in the case of verbs like tell, predict do not obviously support the present account, if non-veridical readings of embedded questions occur after these verbs, which are not constructed with a preposition. This, as a matter of fact, may be the most serious problem for the present account, and the point where one may have to revise the semantics of embedded whether-complements proposed in (40) (see Egré and Spector 2007).

\section{Conclusion}

Let us review briefly the main elements of our account and conclude with a discussion of some problems. Why is it that wonder selects only for interrogative complements, believe only for declarative complements, while know allows for both? Following Groenendijk and Stokhof, we have assumed that the difference between know and wonder is that wonder fundamentally selects for the intension of a question; it does not take that-clauses because this would produce a type mismatch. By contrast, know is a propositional verb, like believe, but because know is veridical, that-complements after know coincide with the extension of the corresponding whether-question: to know that is to know whether, just as to know whether is to know that. Here we have argued that with the exception of assertion predicates (like be true/right that), the same inference pattern is satisfied in principle by all veridical attitude verbs. As for the converse, we have argued that verbs like believe and regret do not embed whether-complements because when that-clauses after such verbs cannot be expressed in the same way as whether-clauses. When nonveridical predicates like agree seem to satisfy the inference from that-to-whether, some coercion mechanism is in fact triggered by the presence of a preposition in front of interrogative complements, in the same way in which believe that licences the inference to have a belief about whether.

How does the present account relate to the ones we examined above? To some extent, our account agrees with Ginzburg's intuition that that-clauses behave differently after believe and after know. But on the present view, that-clauses continue to denote propositions after know and after believe in both cases: the only difference is in the lexical semantics of the verbs, not in the objects they select for. Our account also agrees with Saebo's account on the idea that the use of whether-clauses is pragmatically restricted in a number a contexts, due to a competition with thatclauses. However, on our theory these pragmatic restrictions are not sufficient to explain those cases where the verbs cannot be used. Our account of the admission and exclusion of whether-complements remains fundamentally semantic in this respect.

Here we have assumed that interrogative complements always denote the true answer to the question. An alternative possibility, explored in Egré and Spector 2007, would be to assume that questions systematically denote some potential complete answer to the question, rather than the true answer to the question. Under that assumption, "V whether $p$ " should mean "V $p$ or $\mathrm{V}$ not $p$ ", rather than 
"V whichever of $p$ and $\neg p$ is the true answer" (ie $(p \rightarrow V p) \wedge(\neg p \rightarrow V \neg p)$ ), a distinction that is collapsed, precisely, when the verbs are veridical (see Egré and Spector 2007). If so, however, the that-to-whether constraint would be trivially satisfied, since trivially $V p$ entails $V p \vee V \neg p$. To explain why some propositional verbs like believe or regret do not take whether-complements, we would then need a different story, whereby some semantic feature of those verbs blocks the semantic interpretation in front of questions (as in the accounts reviewed in section 2 and as in the strategy used in section 3.3 to rule out sentences like "it is true whether $p$ "). Such a line of explanation may prove more explanatory and economical in the end. On the present account, the reason why verbs like regret or believe do not embed whether-complements is because they lack a semantic feature (namely veridicality), not because some specific semantic feature would block the interpretation.

A related weakness of the present theory is that we do not explain the unacceptability of believe whether and it is true whether in the same way, where one may feel that the exclusion is of some common origin in both cases. Likewise, as announced in the introduction, our account leaves unexplained why some verbs appear to take wh-questions, despite the fact that they do not take whethercomplements (like surprise). Assuming wh-complements really express questions in such contexts, this may suggest that veridicality is not the right criterion, and that further lexical properties of the embedding verbs come into play (as in Guerzoni 2007). ${ }^{18}$

\section{References}

[1] Abusch D. (2002), "Lexical Alternatives as a Source of Pragmatic Presuppositions”, In SALT XII, Brendan Jackson, ed. CLC Publications, Ithaca NY. 2002.

[2] Baker C. L. (1968), Indirect Questions in English, Phd. Dissertation, University of Illinois at Urbana-Champaign.

[3] Berman S. (1991), The Semantics of Open Sentences, Phd. Dissertation, University of Massachusetts.

\footnotetext{
${ }^{18}$ This paper is based in part of on chapter 5 of my $\mathrm{PhD}$ and derives from earlier work on this topic (Egré 2005). Versions of this paper were presented at different places and conferences since 2005, including at the JSM2005 in Paris, at talks given in linguistics seminars at the University of Paris 7 and Paris 8, at the conference in Linguistics and Epistemology in Aberdeen in 2007, and at the Workshop on Knowledge and Questions organized by F. Lihoreau in Nancy that same year. I am indebted to many people for exchanges and discussions on this topic, including M. Aloni, S. Bromberger, A. Carballo Perez, D. Bonnay, B. Geurts, K. von Fintel, D. Fox, I. Heim, R. Holton, R. Katzir, F. Lihoreau, L. Nash, D. Pesetsky, I. Rumfitt, J. Schaffer, P. Schlenker, R. Singh, B. Spector, R. Stalnaker, T. Williamson, H. Zeevat and R. Zuber. Special thanks are due P. Schlenker and $\mathrm{B}$. Spector for their comments and immensely helpful feedback since the very beginning of this research. I also acknowledge the MIT-France Seed Fund for Collaborative Research, which made it possible for me to write this paper during a stay at the MIT Linguistics \& Philosophy Department (Exchange on "Presuppositions and Implicatures").
} 
[4] Égré P. (2004), Attitudes propositionnelles et paradoxes épistémiques, $\mathrm{PhD}$ Dissertation, IHPST and Université Paris I, Paris.

[5] Égré P. (2005), "Savoir, Croire et questions enchâssées", in P. Schlenker \& D. Sportiche (eds.), Proceedings of Division of Linguistic Labor: The La Bretesche Workshop, 2003; also available in Electronic Publications of Philosophia Scientiae.

[6] Égré P. \& Spector B. (2007), "Embedded Questions Revisited: An Answer, not necessarily The Answer". Manuscript, Harvard \& IJN, presented at JSM 2007, Paris.

[7] Gajewksi J. (2005), Neg-Raising: Polarity and Presupposition, PhD Dissertation, MIT.

[8] Gazdar G. (1979), Pragmatics: Implicature, Presupposition, and Logical Form, Academic Press, New York.

[9] Ginzburg J. (1995), "Resolving Questions : I \& II", Linguistics and Philosophy, 18, pp. 459-527 \& 567-609.

[10] Groenendijk J. \& Stokhof M. (1982), "Semantic Analysis of WhComplements", Linguistics and Philosophy, 5, pp. 117-233.

[11] Groenendijk J. \& Stokhof M. (1990), "Partitioning Logical Space”, ESSLLI 1990 Course Notes.

[12] Guerzoni E. (2007), “Weak Exhaustivity: A Pragmatic Account”, SALT 17.

[13] Heim I. (1991), "Artikel Und Definitheit", in A. von Stechow and D. Wunderlich (eds.), Semantik: Ein internationales Handbuch der zeitgenössischen Forschung, 487-535, de Gruyter, Berlin.

[14] Heim I. (1992), "Presupposition Projection and the Semantics of Attitude Verbs", Journal of Semantics, 9: 183-221.

[15] Heim I. \& Kratzer A. (1998), Semantics in Generative Grammar, Blackwell.

[16] Hintikka J. (1975), "Different Constructions in Terms of the Basic Epistemological Verbs", in The Intentions of Intensionality, Dordrecht : Kluwer, pp. 1-25.

[17] Holton R. (1997), "Some telling examples: a reply to Tsohatzidis", Journal of Pragmatics 28, 625-628.

[18] Holton R. (2006), "Facts, Factives and Anti-Factives", manuscript, MIT.

[19] Huddleston R. and G. Pullum (2002), The Cambridge Grammar of the English Language, Cambridge University Press. 
[20] Karttunen L. (1971), "Some Observations on Factivity", Papers in Linguistics 4:1, 55-69.

[21] Karttunen L. (1977), "Syntax and Semantics of Questions", Linguistics and Philosophy, 1: 3-44.

[22] Karttunen L. (1977b), "To Doubt Whether", The CLS Book of Squibs, Chicago Linguistics Society (scanned version available from Karttunen's webpage).

[23] Klein E. (1975), "Two Sorts of Factive Predicate”, Pragmatic Microfiche, I, 1: B5-C14.

[24] Kiparsky P. and Kiparsky C. (1970), "Fact", in M. Bierwisch and K. Heidolph (eds.), Progress in Linguistics, The Hague: Mouton.

[25] Kratzer A. (2002), "Facts : Particulars or Information Units ?", Linguistics and Philosophy, 25, pp. 655-670.

[26] Lahiri U. (2002), Questions and Answers in Embedded Contexts, Oxford Studies in Theoretical Linguistics, Oxford.

[27] Pustejovsky J. (1993), "Type Coercion and Lexical Selection”. In J. Putejovsky (ed.), Semantics and the Lexicon, Kluwer.

[28] Russell B. (1918), The Philosophy of Logical Atomism, Open Court Classics, LaSalle, Illinois, 1985.

[29] Saebø K. J. (2005), “A Whether Forecast”, in B. ten Cate and H. Zeevat (eds.), TbiLLC 2005, Berlin: Springer 2007, 189-199.

[30] Sauerland U. (2007), "Implicated Presuppositions", in A. Steube (ed), Sentence and Context, Mouton de Gruyter, Berlin.

[31] Schlenker P. (2005), “The Lazy Frenchman's Approach to the Subjunctive (Speculations on Reference to Worlds and Semantic Defaults in the Analysis of Mood)", Proceedings of Going Romance XVII.

[32] Vendler Z. (1972), Res Cogitans, Ithaca, NY : Cornell University Press.

[33] Williamson T. (2000), Knowledge and its Limits, Oxford UP.

[34] Zuber R. (1982), "Semantic Restrictions on Certains Complementizers", Proceedings of the 13th International Congress of Linguists, S. Hattori \& K. Inoue (eds), Tokyo 1982. 